\title{
Image Technology of Display Design Based on Digital Multimedia Implementation
}

\author{
$\mathrm{Hu} \mathrm{Xi}{ }^{1}$, Li Jing ${ }^{1}$ \\ ${ }^{1}$ Zhejiang Business Technology Institute, Ningbo, 315012, China \\ huxi_hx@yeah.net
}

Keywords: Multimedia Technology; Image information system; Display design; Teaching process

\begin{abstract}
Display design is an independent professional design discipline, it is current higher vocational art design speciality students must master a foreign emerging professional courses. In traditional teaching, the author puts forward the practical "through" classification of " $1+1+1$ " display design project curriculum teaching process in order to cultivate students' reform, display design aspects of the professional practice skills, thereby better meet the design thinking and design expression for widening, unity of vocational college students employment channels in the future lay a solid professional foundation.
\end{abstract}

\section{Introduction}

Display design is one of the key course design professional, course not only and indoor space design, visual communication design, industrial product design is closely related to such disciplines, and it also has the message and the characteristics of marketing planning.

In the display design course teaching of the course, the project is divided into various project to complete content. Here in the display design "program design as an example, this paper discusses the practice" "classified" $1+1+1$ "mode in the application of project teaching process.

\section{Display design teaching some enlightenment}

At present, in most of universities and colleges in professional curriculum design are opened display design class, even conditions mature colleges opened directly display design professional. The rapid increase of higher vocational college students for professional teaching, brought many new problems and author display design years when the professional practice and teaching course design experience to see higher vocational display design course teaching has the following features:

\section{Discipline Own Comprehensive and Field of Universality and Industry Characteristics of the Times}

Display design is a rich content and widely and along with the time involved field continuous development and enriching its content subject. it

Including indoor and outdoor exhibition space planning (space space, exhibits on display), graphic visual communication (such as LOGO and brand, graphic), marketing planning (such as marketing objectives, message), etc. Successful presentation design needs mutual fusion space planning, exhibits on display and graphic design, and the structure and material and construction way of understanding. This also objective for the professional teachers, which can penetrate put forward relevant discipline knowledge, and must possess strong their professional and practical ability of "two-qualification" quality teaching requirements.

\section{The Structure of Higher Vocational Colleges Students the Complexity and Diversity}

Due to the convergence of emerging professional, most of students in higher vocational colleges, the modelling of two-tone design based on the understanding and professional interests are impossible to achieve a unified level, the professional teachers in teaching process full of uncertainty and adaptability, based on the above characteristics, aimed at professional teaching and combined with the professional category display design, teachers should spend some time for scientific and reasonable project design curriculum, in order to achieve a quantization, popularization and enhancement. 


\section{The Present this Curriculum Teaching some Enlightenment}

Contemporary environmental art design and display design is with great social demand and rapid development speed and to all worldwide, becoming the new employment channels. But in the display design course of teaching process, at present there is still many problems, to sum up, mainly includes three aspects: (1) the teaching process too much emphasis on the characteristics of each professional disciplines ideas, unilateral, teaching mode single; (2) the students to learn a lack of comprehensive and systematic work process experience; (3) course teaching and industry development linked to not close, constructability is not high.

Therefore, in view of the present this course in higher vocational teaching situation, combining the display design course project teaching mechanism, specifically of vocational display design program "classification practice" teaching process discussion and research.

\section{The display design "project teaching reform ideas}

In the display design course project teaching, curriculum content of various typical were selected to complete the project categories practice teaching "classification, training using" $1+1+1$ "manners, that in each work practice stage, master a typical project categories characteristics, complete a typical project task, key ascend a professional skills. To generate work process as the main line by project teaching, to achieve "teaching, studying, doing" three-in-one.

Project teaching process, for the teachers and students offers a variety of practical choice possibility, enrich the teaching content, strengthen the consciousness of "planning innovation", which is beneficial to teaching atmosphere and improve teaching active effects, and can improve the students' practical ability of the show.

\section{Program in order to "planning innovation" for leading teaching characteristic way}

Display design is not only a space and site planning art and the art of about visual communication, requests the student to have the strong space imagination and modelling ability, familiar with display design scope of new technology, new technology, new material apply. Encourage students to display as much as possible to try new ways at the same time, the basic theories of shows through lecturing and classification program practice, to cultivate students' ability of organization, creativity and implementation capabilities.

When the students finish the through independent or grouping display design project task, students can also through actual cases, more comprehensive understanding display design theory and conception, and improve the students' design ability and practice ability. Therefore, by using "the planning innovation" is the way for the curriculum implementation project "to" teaching process, to improve student's mission to lead a task interest, in the process, natural into relevant professional practice knowledge, design skills, build planning innovation atmosphere, make the student's professional practice skills been gradually ascension.

Using dynamic teaching module way the whole process of display design work experience

Display design work process including "market evaluation analysis", "marketing planning localization" and "plan effect performance", "design implementation processes, control" to display design work process as the main line to organize the research content of project-based curriculum, and makes students to complete tasks designated project modular of operation process to strengthen the practice ability of teaching goal.

The program is based on teaching modules, display industry jobs, job, professional capability required design creative knowledge skills, as the main teaching contents to launch project teaching implementation. "Classification practice" teaching, can will "classroom, field and practice" combine, and each other with dynamic way, through the work of the project task driven "1+1+1" mode of learning to solve on practice, the traditional teaching mode of teaching content and practical skills shortage of abuses. Link 


\section{"classification practice" of "1 $1+1$ " project teaching process applications}

In the display design course project, "classification practice" project teaching implementation are as follows: first will display design work of diversification by function, according to classified professional classification involved skills characteristic, developed typical project teaching modules. To this curriculum development, select the three "classification practice" teaching implementation projects include: (1) the commercial stores kind of display design, (2) culture exhibition design, display design exhibition class. Then, in view of the above each project type characteristic respectively formulate a typical project practice tasks.

"1 $1+1$ " project teaching process model, is above the course of needs to grasp three professional category, through the project analysis - projects - projects synthetic mode decomposition, respectively through to their respective tasks to the project practice, and theory and practice teaching process model one-on-one project. Students work through each specific project task, every experience kind other practice project work process, will key ascend a professional skills, achieve finally improved display design work the teaching goal of comprehensive abilities.

"Classification practice" of "1 $1+1$ " teaching mode, choose the typical display design, implementation project categories in the working process of the main display design for higher education to organize teaching contents, aggrandizement ascension skill training for key, underlines the project tasks and emphasizes the practical working process. To sum up, "classification practice" of "1 $+1+1$ " teaching mode namely:

The first stage of commercial stores display design -- a research concept handbook: visual communication and marketing planning solve the problem

The second phase culture kind display design - a set of surveying and mapping plan: solve showroom examples show the space scheduling problem indoor

The third stage exhibition display design - an exhibition of indoor show originality model: solve the problem show creative planning

Through this process model project teaching students comprehensive mastery of both and system of display design practice thinking and method, and can achieve the learners, popularizing and improve quantitative teaching purpose.

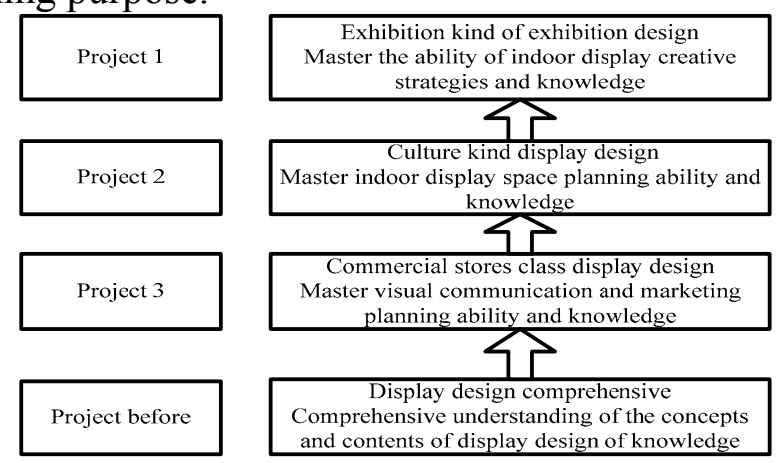

\section{"Commercial stores class show" project - conception (Conceive)}

project analysis: the first stage, mainly through the classification (1) of commercial stores display design practice project site investigation, take the way of working, let each student finally complete a set of PPT research concept manual. Commercial stores class display design (such as clothing, bags, jewelry bracelet or building materials, electronics exhibits, etc) mainly include commercial window, boutique, image gallery, etc, this one phase of the project of class assignments include brand image, visual marketing and the experience economy knowledge and skills of mastery.

project decomposition: students can choose a kind of commercial stores types in the image, research practice, shop drawings, consulting access, graphic records way to truly understand nowadays commercial display design, visual communication and marketing planning related information, and apply the above and information collected, the first complete a normative research appraisal report, evaluation content includes: stores in color, texture, lighting apply; Exhibits display; The displays, display props modelling; Brand LOGO and exhibits to consumer message meets the marketing target effect etc. 
project synthesis: finally, based on field investigation assessment report of the content, form a set of PPT brand sells concept design manual. Students prepare research evaluation report and in the process of making concept manual both learned to show plane layout design method and established the concept of preliminary display design, cultivate the students' professional interest for the next phase of practice teaching laid a foundation. Realized will "classroom, field and practice" with each other, and with dynamic linkage up the way task. Driver project This to quantify the classmate in higher vocational design professional observation and designing idea aspects ability with the preliminary training intuitive and real and effective role.

\section{"Culture class show" project - Design (themselves)}

Project analysis: the second phase, mainly through the classification (2) culture display design practice project of the study, take field measurement record way of working, let each students completing a complete history showroom of surveying and mapping scheme. Case Culture display design mainly include of all kinds of museum, art galleries, art gallery, culture display design more of the main points of design is interior space planning. Campus space form is the student most easy to accept the design concept of place, the conceptual things clear, students must accept after systematic design program teaching, so at this stage to display design main cultivating students' overall planning application ability.

project decomposition: project teaching process, to lead students carry in-the-spot visit and on-site interpretation is given priority to, visit is the author of history showroom already put into use creative practice, and the students are familiar with work and easy and accept and understanding display space type. Visit after this stage explain field measurement records, requires learners grouping field measurement and form, and then back to sketch professional training classrooms, each student combined with a complete set of showroom design drawing for copy.

project synthesis: to generate work process as the main line by project teaching, realized the "teaching, studying, doing" three-in-one. Through such teaching process, learners share display design experience and process, and to promote the overall planning of the understanding of display design, including the exhibition space, the space of the design, flow line of body engineering application, layout, display stadia display design pattern the basic elements of whole set the concept. Copy the work process, paint scheme can systematically popularization students draw standard display design drawings expression ability.

\section{"Exhibition class show" project - realize (Implement)}

project analysis: the third stage, mainly through the classification (3) exhibition display design practice project of case of selecting the manufacture following work style, lets the student in professional model the simulant teach room, grouping creation complete an exhibition show originality model for work task, to understand and implement from drawing design to display project whole space forming. In recent years, with all walks of life rapid economic growth, currently exhibition has become a new hot professional field, the demand for professional staff is demand exceeds supply, thus becomes the design new employment channels of graduates.

Project decomposition: exhibition display industry is a professional \&comprehensive strong industry, to display the marketing planning, site design implementation, exhibition engineering sequence management, structure and materials and construction method, safety control wait for flow has strict requirements and division, which has become the cooperative project teaching process "classification practice" project's focus. Case analysis teaching development way, learners can more comprehensive mastery of the exhibition display, cultivate the comprehensive knowledge skills of learners innovation consciousness (often depends on the level of the ability of design of personal creative thinking ability). Teachers in the theory and practice, under the guidance of soda $40 \mathrm{X} 40 \mathrm{~cm} \mathrm{t}$ set based on real field plane exhibition space proportion the plane and exterior modelling design and model making (shown in figure 1, figure 2), including theme planning design, brand LOGO, marketing planning etc visual communication factors, including indoor and outdoor space form factors of multi-dimensional show. 

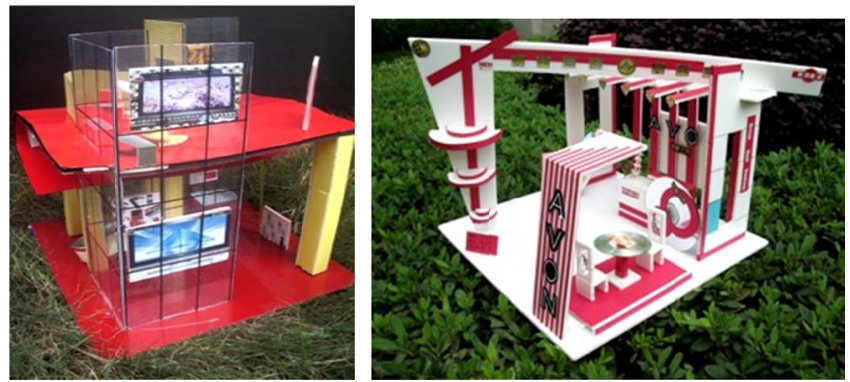

Project synthesis: design the ultimate goal of teaching is to make students form personal capacity, namely the ability to analyze and solve problems. Model making projects exhibition creative way, make the student experience from concept directly to the whole process of creative entity, its shape throughout the display design relevant and professional knowledge, when students the penetration of the concept is curators and designers; Both exhibition work, and exhibits image practitioner of information communication, which dominates in comprehensive summary display design knowledge, improve students' individual brains, the beginning of the creation ability and professional confidence has a positive impact.

\section{The mutual infiltration on relevant professional project teaching to try.}

The teaching of vocational display design, are a largely need major courses of the students' self understanding. Although there are some basic knowledge and principles in language can be taught, but more content in the learning process requires that the student through practice and understanding hand making. Specific teaching, advertising professional focus on visual communication, brand image, ring arts professional focus on spatial form design, display design but in the final analysis to the ultimate goal is to convey information, audience marketing design purpose. Relevant professional mutual infiltration on higher education, such as through the different major attempt between teachers and students in the "classification practice" works display; Relevant professional "such as teachers and students swap" communication way, can a more comprehensive absorb the knowledge display design, shorten the vocational students of fuzzy concept to display design, but for professional teacher asked have abundant professional practice ability and must possess strong teaching curriculum design and control ability.

\section{Acknowledgement}

Zhejiang industry and commerce vocational technology college educational reform subject university-level 2009 (project Numbers: JG200916)

\section{Reference}

[1] Gong Liuzhao. Environmental Art Design [J].Journal of shijiazhuang; Huashan art and literature press, 2002; 41 and 43

[2] Zhu Chun, Deng Yan. Display Design Basis. [M]. Shanghai: Shanghai; Shanghai people's fine arts press, 2006; 19-30

[3] Hong Xiao, Fu Bin Li Difei. Project - based Teaching of Higher Vocational Colleges [J].Journal of Chinese adult education, 2008; (6)

[4] Ying Liheng. Based on work process of course project teaching reform [J].Journal of Chinese vocational and technical education, 2008; (8)

[5] Zhao YaWei. Discuss the design of exhibition space [J]. Chinese science and technology education (project), 2007 (9); 48. 